Tohoku J. Exp. Med., 2008, 214, 231-245

\title{
Coexpression of Menin and JunD during the Duct Cell Differentiation in Mouse Submandibular Gland
}

\author{
Wiphawi Hipkaeo, ${ }^{1}$ Natthiya SaKulsak, ${ }^{1}$ Tomohiko WaKayama, ${ }^{1}$ \\ Miyuki Yamamoto, ${ }^{1}$ Masa-aki NaKaya, ${ }^{1}$ Sunisa KeattikunPairoj, ${ }^{1}$ \\ Mino Kurobo ${ }^{1}$ and ShOICHI IsEKI $^{1}$ \\ ${ }^{1}$ Department of Histology and Embryology, Graduate School of Medical Science, Kanazawa \\ University, Kanazawa, Japan
}

In the submandibular gland (SMG) of mice, a duct portion called the granular convoluted tubule (GCT) is developed preferentially in males with puberty. This sexual dimorphism is androgen-dependent, but the underlying molecular mechanisms are unclear. We have demonstrated that the expression of a transcription factor JunD is regulated in association with the androgen-induced differentiation of GCT cells from striated duct (SD) cells. Menin, a nuclear protein encoded by the MEN1 tumor-suppressor gene, is known to bind JunD, thereby inhibiting its activity. In the present study, we examined the expression of menin in the mouse SMG by use of Northern blotting, Western blotting, and immunohistochemistry. Immunoreactivity for menin was higher in the female than male gland, and localized to the nuclei of intercalated duct cells and a subpopulation of SD cells. In contrast, GCT cells in males appeared negative for menin. The levels of menin in the SMG were increased with castration in males and decreased by repeated administration of testosterone to females or to castrated males. After a single administration of testosterone to females, many SD cells newly gained nuclear menin, which was lost as the cells converted to GCT cells by $48 \mathrm{hrs}$. These patterns of the expression and localization of menin were quite similar to those of JunD. Furthermore, the coimmunoprecipitation analysis of the SMG homogenates indicated that menin binds JunD in vivo. The present study suggests that the JunD-menin complex plays significant roles in the androgen-dependent differentiation of the duct system in the mouse SMG. —— menin; JunD; submandibular gland; differentiation; androgens.

Tohoku J. Exp. Med., 2008, 214 (3), 231-245.

(C) 2008 Tohoku University Medical Press

The submandibular gland (SMG) of rodents is composed of the acinus and the duct system, the postnatal development of which takes place under the control of neuronal and hormonal factors (Jacoby and Leeson 1959; Gresik 1980).
While the proliferation of acinar cells is dependent on the actions of $\beta$-adrenergic agonists (Chang and Barka 1974), the differentiation of duct cells is dependent on the actions of androgens, resulting in a marked sexual dimorphism in

Received November 22, 2007; revision accepted for publication January 23, 2008.

Correspondence: Shoichi Iseki, M.D., Ph.D., Department of Histology and Embryology, Graduate School of

Medical Science, Kanazawa University, 13-1 Takara-machi, Kanazawa 920-8640, Japan.

e-mail: siseki@med.kanazawa-u.ac.jp

Present address for Wiphawi Hipkaeo and Natthiya Sakulsak, Department of Anatomy, Faculty of Medical

Sciences, Naresuan University, Pitsanulok, Thailand. These authors equally contributed to this work. 
the morphology and function of the duct system (Pinkstaff 1980). In the adult mouse and rat SMG, a portion of the duct system called the granular convoluted tubule (GCT) is developed preferentially in males. The epithelial cells of GCT have abundant secretory granules that contain a variety of biologically active peptides, including nerve growth factor (NGF), epidermal growth factor (EGF), transforming growth factor $\beta$, renin, and kallikrein (Barka 1980; Gresik 1994). Castration of the animals readily causes involution of the GCT accompanied by conversion of the phenotype of GCT cells into that of striated duct (SD) cells, whereas administration of androgens to females or castrated males causes the opposite phenomenon (Caramia 1966; Chretien 1977). Such androgen-induced GCT differentiation is accompanied by an upregulation of GCT-specific gene expression (Gubits et al. 1986).

The androgens exert their biological functions by binding to the androgen receptor (AR), a member of the cytoplasmic/nuclear receptors, which is believed to act as a transcription factor in itself by binding to an androgen response element (ARE) located upstream of the androgen-regulated genes (Zhou et al. 1994; Chang et al. 1995). Although AR is expressed in both acinar and duct cells of the rodent SMG (Morrell et al. 1987; Sar et al. 1990), little is known about the mechanism by which the androgen/AR system causes differentiation of the GCT. So far, none of the AREcontaining genes has been shown to play a critical role in the androgen-induced conversion of SD cells into GCT cells, and none of the marker proteins of GCT cells, including EGF and NGF, has been found to have an ARE in its genomic sequence. It is suggested, therefore, that the function of the androgen/AR system in the SMG involves a mechanism distinct from the classical one. Recently, we have found that JunD, a component of the transcription factor activator protein-1 (AP-1), is expressed preferentially in female mouse SMG, where it is located in the nuclei of intercalated duct (ID) cells and a subpopulation of SD cells adjacent to the ID (Hipkaeo et al. 2004). In contrast, mature GCT cells in male SMG are lacking in JunD protein expression. The administration of testosterone to female mice causes a temporary increase in the number of JunD-immunopositive cells in the SD, followed by a loss of JunD immunoreactivity in the GCT cells converted from SD cells. These results suggest cross-talk between the androgen/AR system and membrane receptor-mediated signaling pathways.

AP-1 is a complex composed of members of the Jun family (c-Jun, JunB, and JunD) and Fos family (c-Fos, FosB, Fra1, and Fra2), the protooncogene-encoded nuclear proteins. The Jun family members form homo- or heterodimers among themselves or heterodimers with the Fos family members and bind to the AP- 1 consensus DNA sequence (12-O-tetradecanoylphorbor-13acetate-responsive element [TRE]) located in the promoter region of a variety of target genes (Vogt and Bos 1990; Angel and Karin 1991). Compared with other AP-1 components, JunD is unique in that it functions in cell differentiation rather than cell proliferation and transformation, that it is expressed constantly in a variety of tissues rather than being induced as an early-responsive gene product, and that it binds specifically to menin. Menin, a 610-amino-acid nuclear protein, is the product of the multiple endocrine neoplasia type 1 (MEN1) gene, mutation of which is known to cause a human autosomal dominant syndrome characterized by tumors of the parathyroid, endocrine pancreas, and anterior pituitary (Chandrasekharappa et al. 1997). Menin is expressed in a variety of human and rodent cell lines and tissues (Maruyama et al. 1999; Wautot et al. 2000). In in vitro experimental systems, menin binds to JunD and suppresses its transcriptional activity (Agarwal et al. 1999).

In the present study, we examined the expression and localization of menin at the levels of mRNA and protein in the mouse SMG treated or untreated with testosterone, and compared them with those of JunD. The result showed that menin behaves essentially the same way as JunD in association with the sexual dimorphism and testosterone-induced differentiation of the duct system. Rather unexpectedly, such andogen- 
dependency in JunD and menin expression was observed only in the levels of the protein, not in those of the mRNA.

\section{Materials ANd Methods}

\section{Animals and preparation of tissues}

Male and female Slc:ddY mice, some of which underwent a testectomy or ovariectomy at 6 week (W) of age, were purchased from Nippon SLC, Hamamatsu, Japan and grown until $8 \mathrm{~W}$ of age (adulthood) under standard 12-hrs light/12-hrs dark laboratory conditions with free access to standard food and water. All subsequent procedures were conducted in accordance with the Guidelines for the Care and Use of Laboratory Animals at Kanazawa University. Groups of 5 adult animals and 3 animals at various postnatal ages between $1 \mathrm{~W}$ and $8 \mathrm{~W}$ were used without hormone treatment. Groups of 3 normal male, normal female, testectomized male, and ovariectomized female adults were subjected to subcutaneous injections of $25 \mathrm{mg} / \mathrm{kg}$ of testosterone (Wako Pure Chemical Industries, Osaka) dissolved in olive oil, or the vehicle alone, every 24 hrs for 4 consecutive days and sacrificed at $6 \mathrm{hrs}$ after the last injection. In another experiment, groups of 3 normal female mice were administered a single subcutaneous injection with $50 \mathrm{mg} /$ $\mathrm{kg}$ of testosterone and sacrificed at $6 \mathrm{hrs}, 24 \mathrm{hrs}$, and 48 hrs after the injection. All animals were anesthetized with an intraperitoneal injection of sodium pentobarbital $(50 \mathrm{mg} / \mathrm{kg})$ and sacrificed by bleeding from the right atrium followed by transcardial perfusion with cold physiological saline. To make tissue homogenates for Northern blotting and Western blotting, the SMG were dissected out, frozen immediately in liquid nitrogen, and stored at $-80^{\circ} \mathrm{C}$ until use. To make tissue sections for immunohistochemistry (IHC), the animals were fixed by perfusion with cold $4 \%$ paraformaldehyde in $0.1 \mathrm{M}$ phosphate buffer $(\mathrm{pH}$ 7.2), and the SMG were dissected out. They were further fixed by immersion in the same fixative for $4 \mathrm{hrs}$ at $4^{\circ} \mathrm{C}$, rinsed in $0.1 \mathrm{M}$ phosphate buffer, and then dehydrated in ethanol series and embedded in paraffin. Sections $6 \mu \mathrm{m}$ thick were made with a microtome and mounted on silanized glass slides (Dako, Glostrup, Denmark).

\section{Preparation of probes}

Total RNA was extracted from the frozen specimens of female mouse SMG with the guanidinine-phenolchloroform method using a commercial solution (TRI reagent; Sigma-Aldrich Co., St. Louis, MO, USA), as described previously (Kim et al. 2001). From this RNA, cDNA fragments approximately $500 \mathrm{bp}$ in length for mouse menin (GenBank accession number, NM_008583) and JunD (X15358) were generated by reverse transcription-polymerase chain reaction (RT-PCR) and cloned into the plasmid pGEM3Zf(+) (Promega, Madison, WI, USA). For Northern blotting, the cDNA probes were cut out of the plasmids and labeled with $\left[\alpha-{ }^{32} \mathrm{P}\right] \mathrm{dCTP}$ (Dupont, Wilmington, DE, USA) using a Megaprime DNA labeling system (Amersham Pharmacia Biotech, Uppsala, Sweden). The cDNA probes for glyceraldehyde 3-phosphate dehydrogenase (GAPDH), a house-keeping gene product (M32599), and NGF, a GCT-specific marker protein (M35075), were also prepared in the same way.

\section{Northern blotting}

Total RNA was extracted from the SMG as described for preparation of the probes. Twentymicrogram aliquots of the RNA samples were denatured by glyoxal and electrophoresed in $1 \%$ agarose gels, as described previously (Kim et al. 2001). As a molecular size marker, an RNA ladder (Life technologies, Inc., Rockville, MD, USA) was used. The samples were then blotted onto nylon membranes (Pall BioSupport, East Hills, NY, USA) and cross-linked by UV irradiation. The membranes were first pre-hybridized at $65^{\circ} \mathrm{C}$ for $2 \mathrm{hrs}$ in $1 \mathrm{M} \mathrm{NaCl}, 50 \mathrm{mM}$ Tris-HCl $(\mathrm{pH}$ 7.5), $10 \times$ Denhardt's solution, $0.1 \%$ Sarkosyl, $10 \mathrm{mM}$ EDTA and $250 \mu \mathrm{g} / \mathrm{ml}$ denatured salmon sperm DNA, and then hybridzed in the same solution with ${ }^{32} \mathrm{P}$-labeled menin and JunD cDNA probes. After incubation at $65^{\circ} \mathrm{C}$ overnight, the membranes were washed extensively in $6 \times \mathrm{SSC}(1 \times \mathrm{SSC}$ contains $150 \mathrm{mM}$ sodium chloride and $15 \mathrm{mM}$ sodium citrate, $\mathrm{pH} 7.0$ ) containing $0.1 \%$ Sarkosyl at $65^{\circ} \mathrm{C}$. The same or separately prepared membranes were also hybridized with the cDNA probes for NGF and GAPDH. The radioactivity of the hybridization bands in the membranes was first quantified with a BAS2000 BioImage Analyzer (Fuji Photo Film Co., Hamamatsu). Subsequently, the membranes were exposed to X-ray film (Kodak X-OMAT AR) for 1 to 5 days with an intensifying screen at $-80^{\circ} \mathrm{C}$ for autoradiography. The relative radioactivity of the hybridization band for menin or JunD mRNA, after being normalized with the corresponding value for GAPDH mRNA, was obtained as the mean \pm standard deviation (s.D.) of 3 to 5 samples.

Preparation of the primary antibodies

Rabbit polyclonal antibodies against menin and 
JunD were purchased from Santa Cruz Biotechnology (Santa Cruz, CA, USA), sheep polyclonal anti-NGF antibody was from Chemicon (Temecula, CA, USA), and mouse monoclonal anti- $\alpha$-tubulin antibody was from Sigma (St. Louis, MO, USA). Rat polyclonal anti-menin antibody was produced in our laboratory according to methods described previously (Wakayama et al. 2006). Briefly, a recombinant oligopeptide for menin, which was the C-terminal 39 amino acids of menin fused with the carrier protein glutathione-S-transferase, was produced in bacteria, emulsified with adjuvant, and injected into the hind footpads of rats. A booster injection was made two weeks later, and sera were collected one week after the booster.

\section{Western blotting}

Cell lysates were prepared from the frozen mouse SMG specimens, electrophoresed in a $15 \%$ polyacrylamide gels in the presence of $0.1 \%$ SDS, and transferred to PVDF membranes as described previously (Hipkaeo et al. 2004). After treatment with 5\% non-fat skim milk in PBS, the membranes were incubated with rabbit antimenin antibody $(0.1 \mu \mathrm{g} / \mathrm{ml})$, rabbit anti-JunD antibody $(0.1 \mu \mathrm{g} / \mathrm{ml})$, sheep anti-NGF antibody $(0.05 \mu \mathrm{g} / \mathrm{ml})$, or rabbit anti- $\alpha$-tubulin antibody $(1: 10,000)$ overnight at $4^{\circ} \mathrm{C}$. After washing, the membranes were incubated with horseradish peroxidase-conjugated anti-rabbit IgG antibody or anti-sheep IgG antibody (Dako, Glostrup, Denmark) at $1: 2,000$ for $1 \mathrm{hr}$. The immunoreaction was detected with X-ray film after treatment of the membranes with the chemiluminescence kit ECL-plus (Amersham Pharmacia Biotech, Uppsala, Sweden). The developed X-ray film was converted to an image file by scanning with an Epson GT-9800F scanner and the optical density of the immunoreactive band was quantified with Image Gage version 3.41 software (Fuji Photo Film, Co., Tokyo). The relative intensity of the immunoreactive band for menin or JunD mRNA, after being normalized with the corresponding value for tubulin, was obtained as the mean \pm S.D. of 5 or 3 samples.

\section{Immunoprecipitation}

A cell lysate from adult female SMG containing 200 $\mu \mathrm{g}$ of protein was preabsorbed with protein $\mathrm{G}$-agarose (Roche Diagnostics, Mannheim, Germany) for $3 \mathrm{hrs}$ at $4^{\circ} \mathrm{C}$. After centrifugation, the supernatant was incubated with $10 \mu \mathrm{g}$ of rabbit anti-menin, rabbit anti-JunD, or rat anti-JunD antibody for $2 \mathrm{hrs,}$, and then incubated with protein G-agarose for $3 \mathrm{hrs}$ at $4^{\circ} \mathrm{C}$. After centrifugation, the immunoprecipitated products were subjected to Western blotting as described above, using rabbit antimenin or rat anti-JunD antibody.

IHC

IHC was performed in the paraffin sections of SMG using rabbit anti-menin, rabbit anti-JunD, rat anti-JunD, and sheep anti-NGF antibodies. After deparaffinization in xylen, the sections were pre-treated successively with $0.3 \%$ Tween 20 in PBS for $1 \mathrm{hr}, 0.3 \% \mathrm{H}_{2} \mathrm{O}_{2}$ in methanol for $10 \mathrm{~min}$ and $3 \%$ normal swine serum for $30 \mathrm{~min}$. For IHC by the enzyme-detection method, the sections were incubated overnight at room temperature with rabbit antimenin or anti-JunD antibody at a concentration of 0.5 $\mu \mathrm{g} / \mathrm{ml}$, or sheep anti-NGF antibody at a concentration of $0.25 \mu \mathrm{g} / \mathrm{ml}$. To confirm the specificity of the immunoreaction, the antibodies were absorbed with the respective peptide antigens supplied by the manufacturer at 100 $\mu \mathrm{g} / \mathrm{ml}$ for $1 \mathrm{hr}$ at $4^{\circ} \mathrm{C}$ prior to use. After a wash with PBS, the sites of immunoreaction were visualized by incubating the sections successively with biotinylated anti-rabbit IgG or anti-sheep IgG antibody (Vector Laboratories, Burlingame, CA, USA) at a $1: 200$ dilution for $1 \mathrm{hr}$, horseradish peroxidase-conjugated streptavidin (Dako) at a 1:300 dilution for $1 \mathrm{hr}$, and $0.01 \%$ diaminobenzidine tetrahydrochloride in the presence of $0.02 \%$ $\mathrm{H}_{2} \mathrm{O}_{2}$ in $50 \mathrm{mM}$ Tris- $\mathrm{HCl}$, pH 7.5 for about $15 \mathrm{~min}$. The sections were subjected to observation under an Olympus BX50 microscope. For fluorescent double-immunostaining, the pretreated sections were incubated with a mixture of rabbit anti-menin antibody $(4 \mu \mathrm{g} / \mathrm{ml})$ and sheep anti-NGF antibody $(1 \mu \mathrm{g} / \mathrm{ml})$ overnight at $4^{\circ} \mathrm{C}$. After being washed, the sections were incubated with a mixture of Cy3-labeled anti-rabbit IgG antibody $(6.5 \mu \mathrm{g} / \mathrm{ml})$ and Cy2-labeled anti-goat $\mathrm{IgG}$ antibody $(32.5 \mu \mathrm{g} / \mathrm{ml})$ (Jackson ImmunoResearch Laboratories, West Grove, PA, USA) for $1 \mathrm{hr}$. They were then mounted in glycerol and subjected to observation with an Olympus BX50/ BX-FLA fluorescent microscope.

\section{Statistical analyses}

The statistical difference between two mean values was examined by Student's $t$-test, and the difference with $p<0.05$ was considered significant.

\section{Results}

Sexual dimorphism in the expression of menin and JunD in the SMG

The Western blot analysis of cell lysates 
from the adult male and female SMG revealed a marked sex difference in the production of menin and JunD (Fig. 1A). Both proteins had a more intense immunoreactive band (molecular weight, $67 \mathrm{kDa}$ for menin and $39 \mathrm{kDa}$ for JunD) in the female than male gland. With the quantitative analysis of the immunoreactive bands, the relative levels of menin and JunD, after normalization with the levels of tubulin, were found to be 2.0 times and 5.2 times higher, respectively, in the female than male gland (Fig. 1B). However, the Northern blot analysis of total RNA from the adult male and female SMG demonstrated no significant difference between sexes in the level of either menin or JunD mRNA, as judged by the intensity of the corresponding hybridization bands (molecular size, $2.5 \mathrm{~kb}$ for menin and $2.0 \mathrm{~kb}$ for JunD) normalized with the GAPDH bands (Fig. 2A, B).
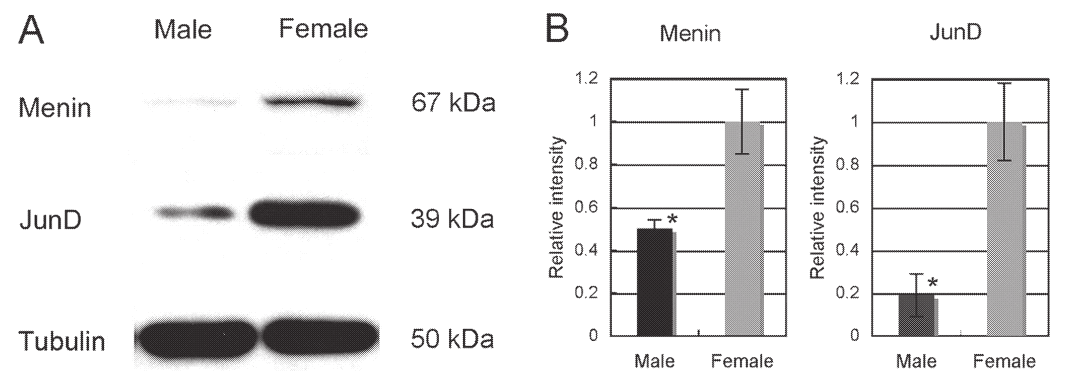

Fig. 1. Western blot analysis showing the expression of menin and JunD in the submandibular glands of male and female mice.

A: The protein samples were electrophoresed, blotted and immunostained with anti-menin and antiJunD antibodies. For comparison, staining with anti- $\alpha$-tubulin antibody was also performed. A representative result is shown. The molecular weights $(\mathrm{kDa})$ of the immunoreactive bands are indicated. B: Relative intensity represents the density of the menin and JunD bands from male and female samples divided by that of the corresponding $\alpha$-tubulin bands and is presented as the mean \pm S.D. of 5 samples. For both menin and JunD, the female values are set at $1 .{ }^{*}$ Significantly different from the female value $(p<0.05)$.
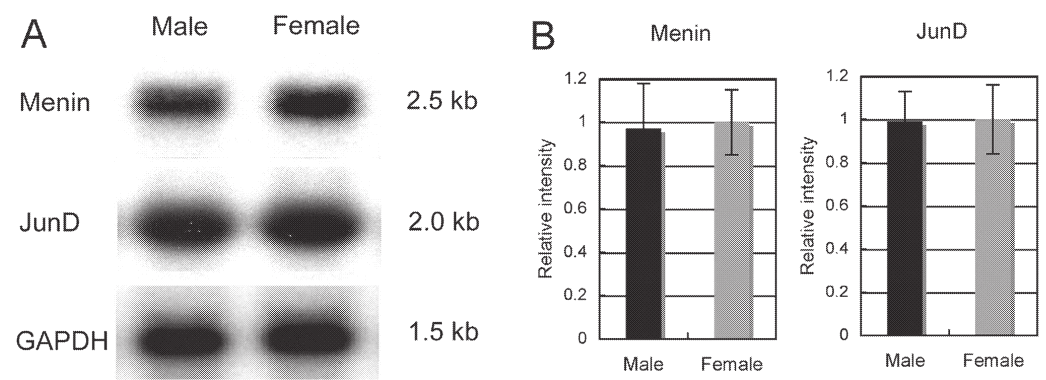

Fig. 2. Northern blot analysis showing the expression of the mRNA for menin and JunD in the submandibular glands of male and female mice.

A: The total RNA samples were electrophoresed, blotted, and hybridized with ${ }^{32} \mathrm{P}$-labeled cDNA probes for menin and JunD. For comparison, hybridization with the GAPDH probe was also performed. A representative autoradiogram is shown. The sizes of the hybridized bands $(\mathrm{kb})$ are indicated. B: Relative intensity represents the radioactivity of the menin and JunD bands from male and female samples divided by that of the corresponding GAPDH bands and is presented as the mean \pm S.D. of 5 samples. For both menin and JunD mRNA, the female values are set at 1 . There is no significant difference between male and female values. 
Dependency of the expression of menin and JunD on androgens

To clarify if the observed sex difference in the levels of menin and JunD proteins in the mouse SMG results from hormonal regulation, the effects of testectomy and ovariectomy as well as testosterone administration daily for 4 days on menin and JunD expression in the SMG were

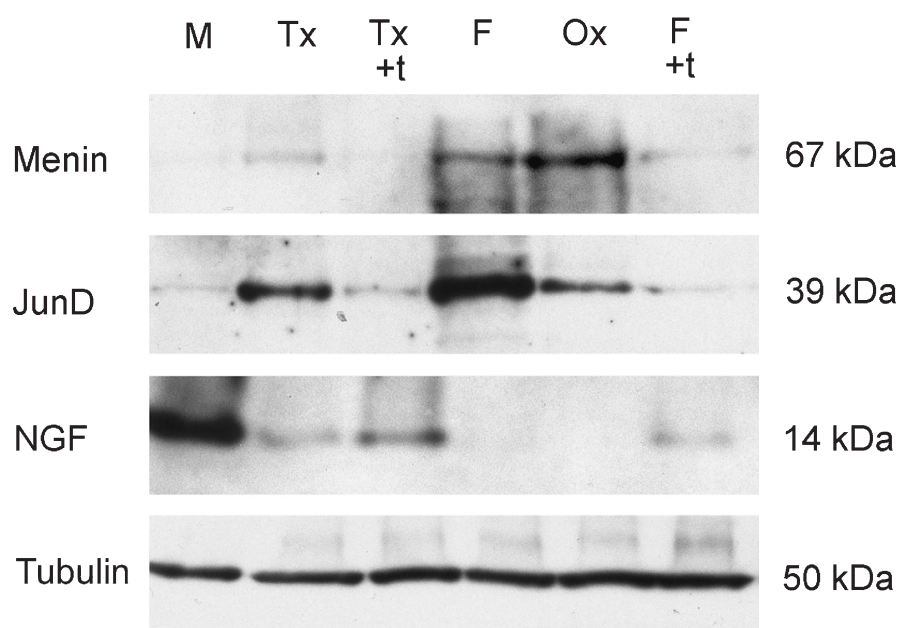

Fig. 3. Western blot analysis showing the expression of menin, JunD, and NGF in the submandibular glands of mice in various hormonal conditions.

The protein samples from the male $(\mathrm{M})$, testectomized male $(\mathrm{Tx})$, testosterone-treated testectomized male $(\mathrm{Tx}+\mathrm{t})$, female $(\mathrm{F})$, ovariectomized female $(\mathrm{Ox})$, and testosterone-treated female $(\mathrm{F}+\mathrm{t})$ mice were electrophoresed, blotted and immunostained with the antibodies against menin, JunD and NGF. For comparison, staining with anti- $\alpha$-tubulin antibody was also performed. A representative result is shown. The molecular weights $(\mathrm{kDa})$ of the immunoreactive bands are indicated.

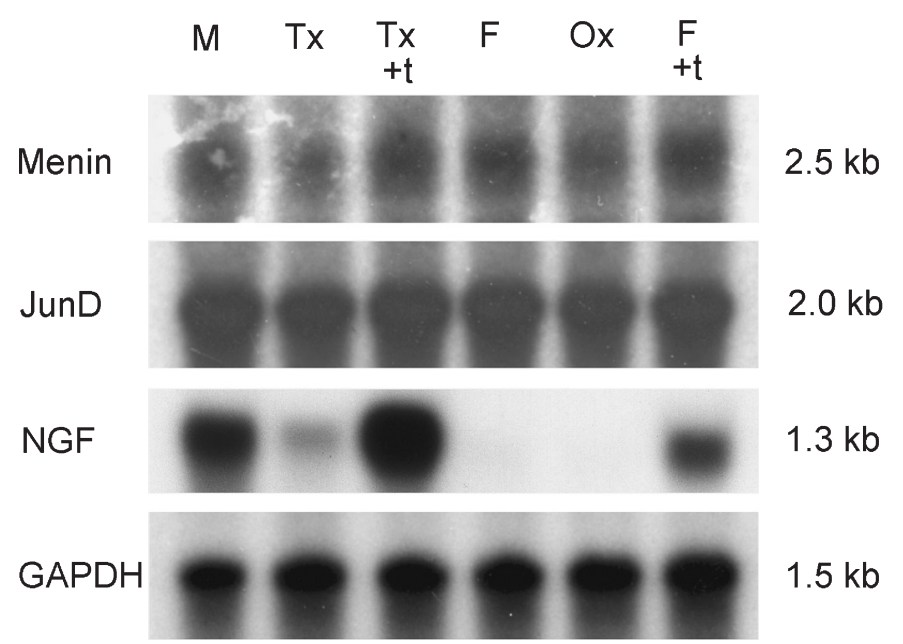

Fig. 4. Northern blot analysis showing the expression of the mRNA for menin, JunD, and NGF in the submandibular glands of mice in various hormonal conditions.

The total RNA samples from the male (M), testectomized male (Tx), testosterone-treated testectomized male $(\mathrm{Tx}+\mathrm{t})$, female $(\mathrm{F})$, ovariectomized female $(\mathrm{Ox})$, and testosterone-treated female $(\mathrm{F}+\mathrm{t})$ mice were electrophoresed, blotted and hybridized with ${ }^{32} \mathrm{P}$-labeled cDNA probes for menin, JunD, and NGF. For comparison, hybridization with the GAPDH probe was also performed. A representative autoradiogram is shown. The sizes of the hybridized bands $(\mathrm{kb})$ are indicated. 
examined. As shown by Western blotting, testectomy caused a substantial increase in the levels of both menin and JunD proteins, and the replacement of testosterone readily reversed this, in the male SMG (Fig. 3). Ovariectomy caused no changes, whereas the administration of testosterone caused a substantial decrease, in the levels of both menin and JunD in the female SMG. The effectiveness of testectomy and testosterone administration in this experiment was verified by the finding that levels of NGF mRNA were substantially higher in the SMG from normal male, testosterone-administered testectomized male and testosterone-administered female animals than those from testectomized male, normal female, and ovariectomized female animals. With Northern blotting, in contrast, no effect of testectomy or testosterone administration was detected on the levels of menin and JunD mRNA in the SMG (Fig. 4). These results suggest that androgens, and not the ovary-derived hormones, are primarily responsible for the sexual dimorphism in menin and JunD expression in the mouse SMG. Furthermore, this sexual dimorphism exists only in the level of protein, not in that of mRNA.

\section{Localization of menin and JunD in the duct system of the SMG}

In serial paraffin sections of the SMG immunostained for menin, JunD, and NGF, the duct system of the male gland was largely occupied by the GCT, the epithelial cells of which contain NGF-immunopositive secretory granules (Fig. 5C). In contrast, the SD occupied the largest part of the duct system of the female gland, with only a small number of NGF-positive GCT cells scat-
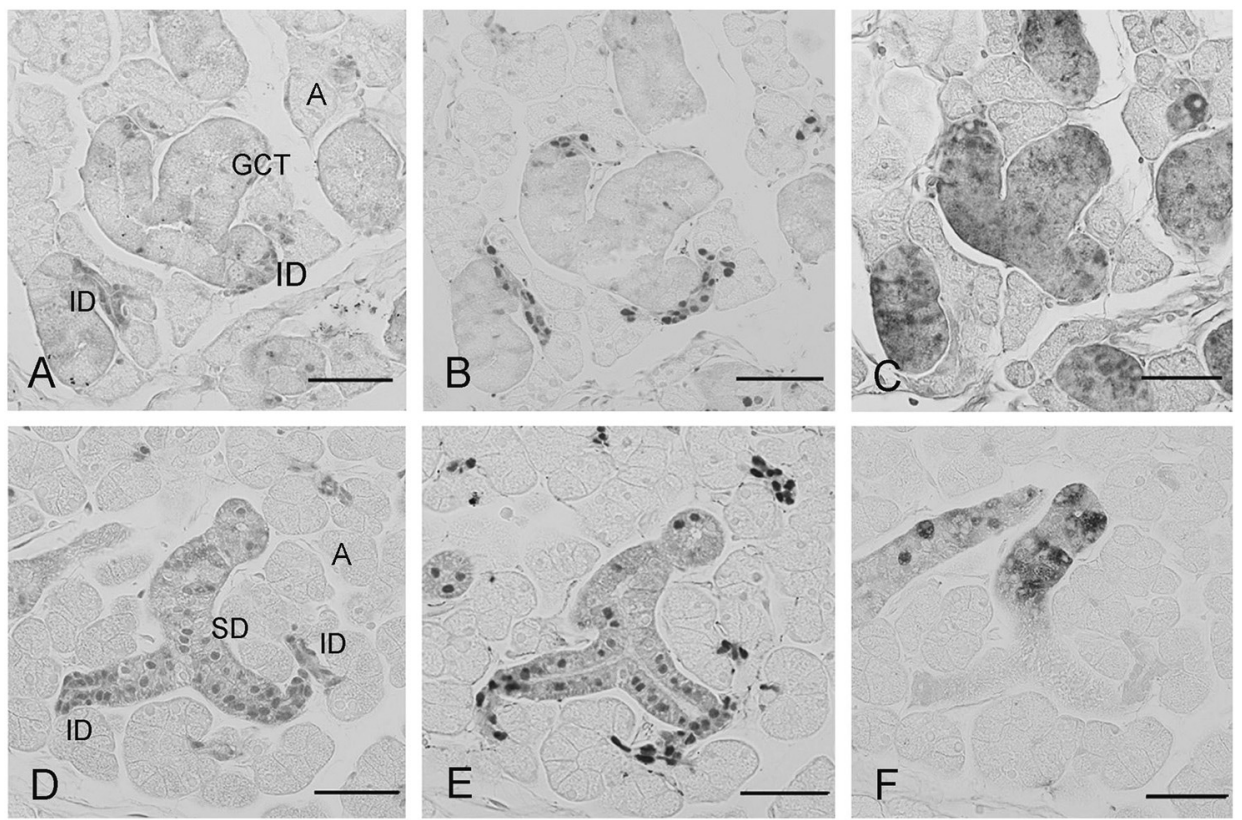

Fig. 5. Immunohistochemical localization of menin, JunD, and NGF in adult male and female submandibular glands.

Serial paraffin sections of male $(\mathbf{A}, \mathbf{B}, \mathbf{C})$ and female $(\mathbf{D}, \mathbf{E}, \mathbf{F})$ glands were immunostained with antibodies against menin $(\mathbf{A}, \mathbf{D}), \operatorname{JunD}(\mathbf{B}, \mathbf{E})$, and NGF $(\mathbf{C}, \mathbf{F})$. A, B: The duct system of the male gland is composed mostly of the ID and GCT. Both menin and JunD are present in the nuclei of ID cells but absent in the nuclei of GCT cells. D, E: The duct system of the female gland is composed mostly of the ID and SD. Both menin and JunD are present in the nuclei of ID cells and cells located in the distal portions of the SD adjacent to the ID. C, F: NGF-immunopositive GCT cells occupy most of the duct portions other than the ID in the male gland but are scattered in a small number among immunonegative cells in the distal portions of the SD in the female gland. Acinar cells (A) are immunonegative for all three factors. Bar $=50 \mu \mathrm{m}$. 
tered among SD cells (Fig. 5F). In the male gland, the immunostaining for both menin and JunD was localized exclusively to the nuclei of ID cells and not detected in GCT cells, or in acinar cells (Fig. 5A, B). In the female gland, in contrast, immunoreactivity for both factors was localized to the nuclei of not only ID cells but also cells occupying the distal portions of the SD that are adjacent to the ID. Most of the SD cells located far from the ID, as well as acinar cells, were immunonegative for menin or JunD (Fig. $5 \mathrm{D}, \mathrm{E})$. When the antibodies were preabsorbed with the respective antigen polypeptides, no immunostaining was obtained in any cell or structure (picture not shown).

Interaction of menin and JunD proteins in vivo

The coordinated hormonal regulation of the expression of menin and JunD as well as their coordinated nuclear localization in a specific subpopulation of duct cells suggests that the two factors function in combination in the SMG. To clarify this issue, we performed immunoprecipitation with cell lysate from the female mouse SMG using anti-JunD and anti-menin antibodies and analyzed the products with Western blotting. As shown in Fig. 6, the anti-JunD antibody detected a $39-\mathrm{kDa}$ immunoreactive band not only in the cell lysate and anti-JunD-immunoprecipitated product but also in the anti-menin-immunoprecip-

A
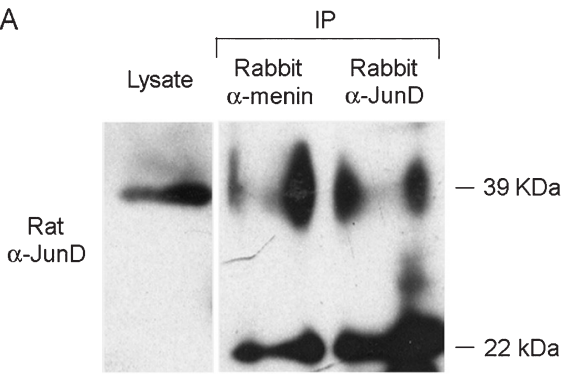

itated product. Conversely, the anti-menin antibody detected a $67-\mathrm{kDa}$ band not only in the cell lysate and anti-menin-immunoprecipitated product but also in the anti-JunD-immunoprecipitated product. These results indicate that menin and JunD bind each other in the nuclei of duct epithelial cells in the SMG.

Postnatal changes in the expression and localization of menin

We then examined changes in the expression and localization of menin during the postnatal development of the male and female SMG. Early in the postnatal period at 1-2 W, the duct system was composed of the ID and SD. Menin immunoreactivity was present in most of the cell nuclei in the duct system in both male and female glands (Fig. 7A, C). At 4-6 W, extensive differentiation of SD cells into GCT cells occurred in the male duct system, whereas the female duct system continued to be composed mostly of SD cells. The ratio of immunopositive duct cells decreased in both male and female glands during this period, but the extent of the decrease was substantially larger in the male than female gland, because of the absence of menin immunoreactivity in the differentiated GCT cells (Fig. 7B, D). In the female gland, cells of the proximal portions of the SD lost menin immunoreactivity whereas those of the distal portions maintained it at $6 \mathrm{~W}$. These results

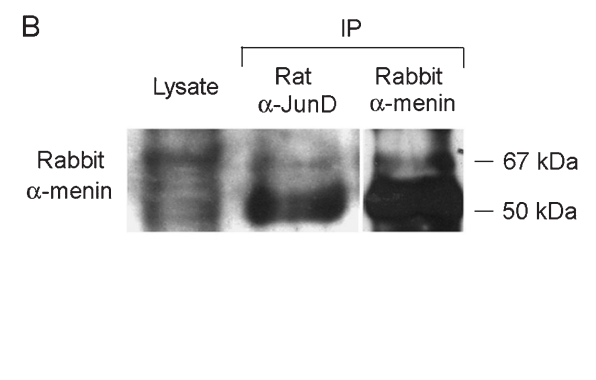

Fig. 6. Interaction between menin and JunD in the submandibular gland.

Cell lysate of adult female SMG was immunoprecipitated with antibodies against menin and JunD. A: The cell lysate and the products of precipitation with rabbit anti-menin and rabbit anti-JunD antibodies were electrophoresed, blotted and stained with rat anti-JunD antibody. B: The cell lysate and the products of precipitation with rat anti-JunD and rabbit anti-menin antibodies were electrophoresed, blotted and immunostained with rabbit anti-menin antibody. The 39-kDa and 67-kDa bands represent JunD and menin, respectively. The 22-kDa and 50-kDa bands represent the light and heavy immunoglobulin chains, respectively. 

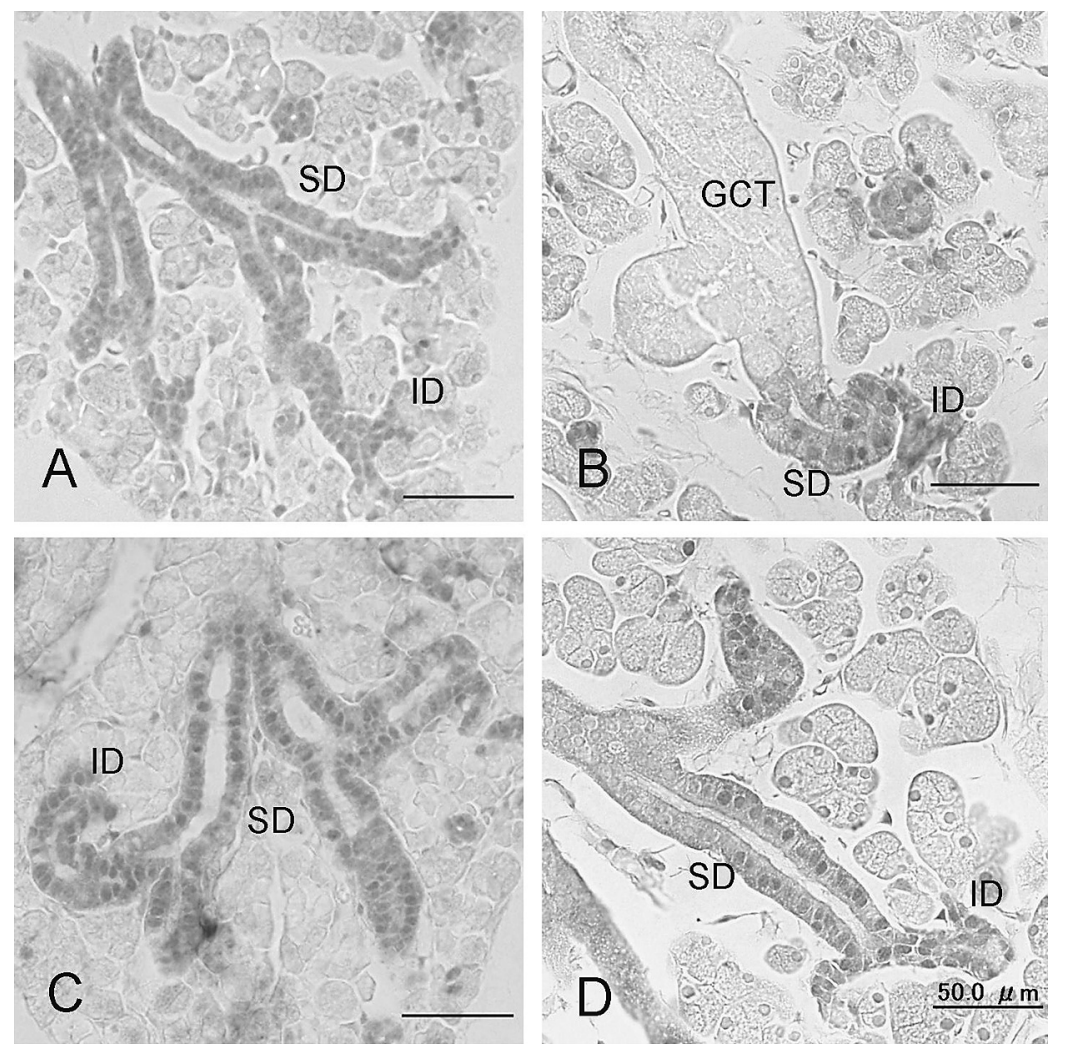

Fig. 7. Immunohistochemical localization of menin in the duct system of male and female submandibular glands during postnatal development.

Sections of male $(\mathbf{A}, \mathbf{B})$ and female $(\mathbf{C}, \mathbf{D})$ glands at $2 \mathrm{~W}(\mathbf{A}, \mathbf{C})$ and $5 \mathrm{~W}(\mathbf{B}, \mathbf{D})$ postpartum were immunostained with anti-menin antibody. A, C: The duct system is composed of ID cells and SD cells, all of which are immunostained in the nuclei, in both male and female glands. B: The duct system is composed of ID cells, a small number of remaining SD cells adjacent to the ID, and abundant GCT cells. The immunoreactivity is positive in the nuclei of ID and SD cells but negative in GCT cells. D: The duct system is composed of ID cells and abundant SD cells. The immunoreactivity is positive in the nuclei of ID cells and a majority of SD cells. Bar $=50 \mu \mathrm{m}$.

suggest that menin protein disappears from the duct cell nuclei in association with the postnatal development of GCT cells, which is known to be androgen-dependent (Chretien 1977). Similar patterns of postnatal expression in the SMG were obtained by us for JunD protein with quantitative analyses (Hipkaeo et al. 2004).

\section{Effect of testosterone on the expression and localization of menin}

To further clarify their relationship with GCT-cell differentiation, the expression and localization of menin in the SMG were examined in due course after a single administration of testosterone to adult female mice. Six to $24 \mathrm{hrs}$ after a subcutaneous injection of $50 \mathrm{mg} / \mathrm{kg}$ of testosterone, there was a temporary rise in the number of immunopositive nuclei in the duct system (Fig. 8A-C). Many immunopositive cell nuclei newly appeared in the proximal portions of the $\mathrm{SD}$, in addition to those in the ID and distal portions of the SD. By 48 hrs after the injection, the majority of SD cells had converted to GCT cells with clear secretory granules similar to those of the male gland. Menin immunoreactivity was no longer present in the nuclei of differentiated GCT cells (Fig. 8D). When double-immunostaining for NGF and menin was performed in the gland 24 hrs after the injection of testosterone, most of the cells positive for cytoplasmic NGF were negative 


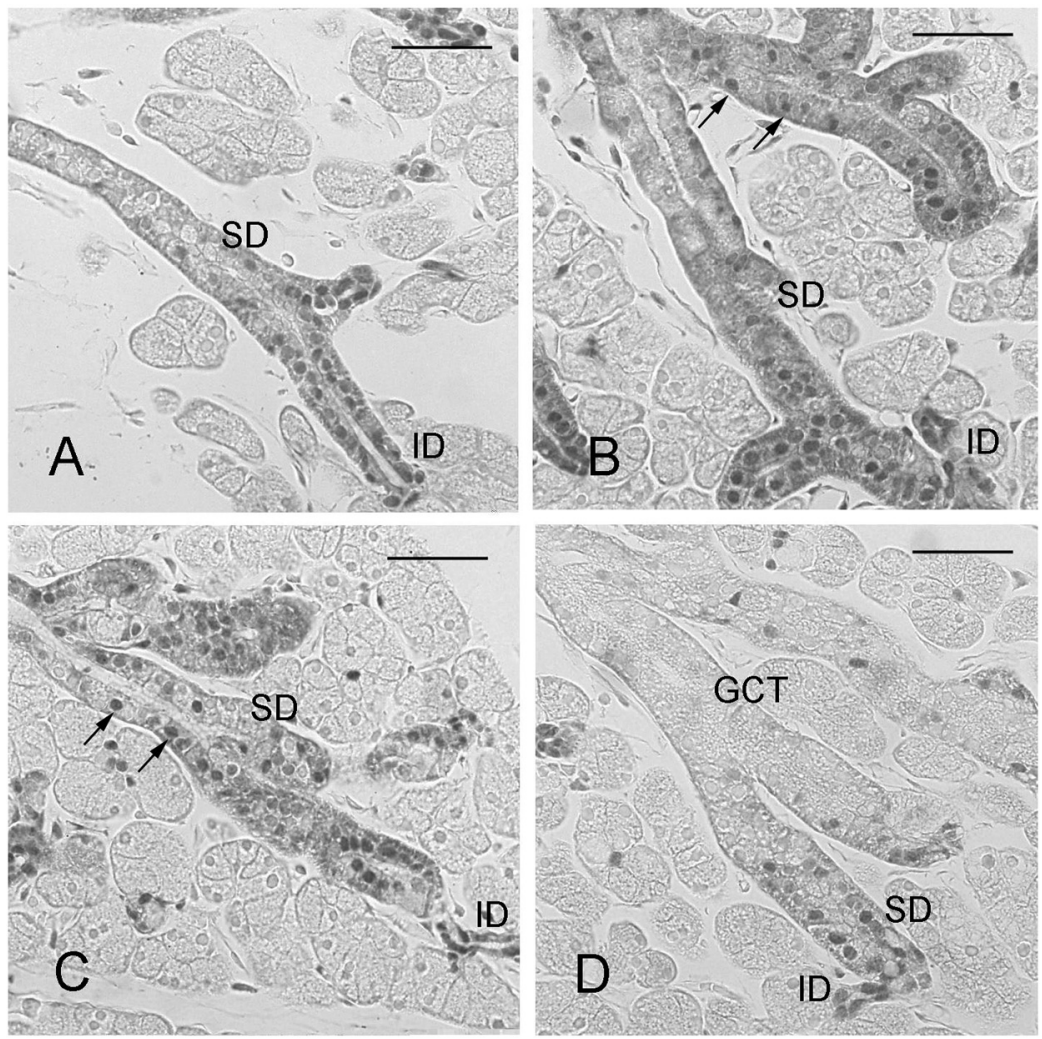

Fig. 8. Immunohistochemical localization of menin in the female submandibular gland stimulated with testosterone.

Sections of adult female glands at $0 \mathrm{hr}(\mathbf{A}), 6 \mathrm{hrs}$ (B), $24 \mathrm{hrs}$ (C), and $48 \mathrm{hrs}$ (D) after testosterone injection were immunostained with anti-menin antibody. A: Menin immunoreactivity is localized to the nuclei of ID cells and the cells located in the distal portions of the SD adjacent to the ID. B, C: Many SD cells in the middle and distal portions of the SD have turned positive for nuclear immunoreactivity (arrows). D: Most of the SD cells have been replaced by GCT cells, which are negative for nuclear immunoreactivity. Only ID cells and a small number of remaining SD cells adjacent to the ID are immunopositive. Bar $=50 \mu \mathrm{m}$.
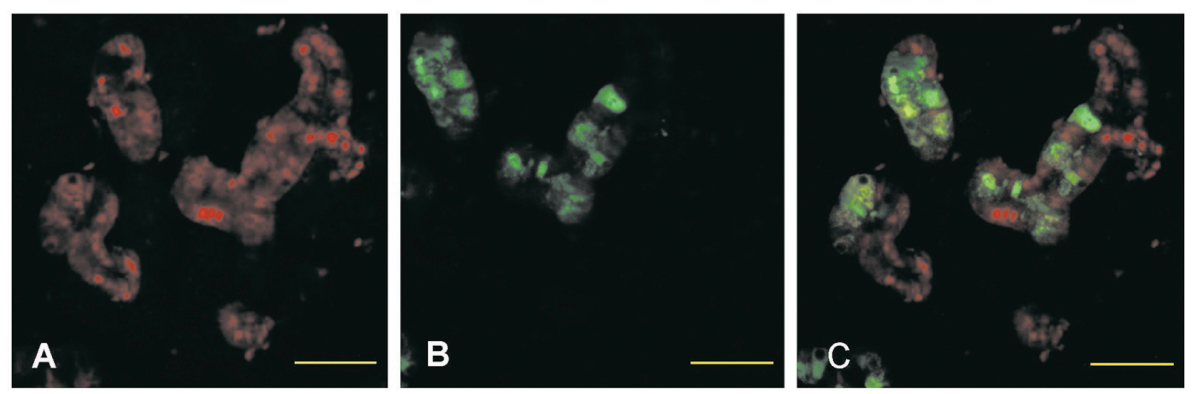

Fig. 9. Double immunostaining for menin and NGF in the female gland $24 \mathrm{hrs}$ after the injection of testosterone.

A: Nuclear JunD immunoreactivity is shown with red fluorescence. B: Cytoplasmic NGF immunoreactivity is shown with green fluorescence. C: A merged picture of A and B shows that nuclear JunD and cytoplasmic NGF do not occur in the same cells. Bar $=50 \mu \mathrm{m}$. 
for nuclear JunD, and most of the cells positive for nuclear menin were negative for cytoplasmic NGF (Fig. 9A-C). These results suggest that menin protein is temporarily induced to accumulate in the nuclei of SD cells by testosterone but is lost from the nuclei of GCT cells after their differentiation from SD cells. Similar patterns of expression in the SMG after the administration of testosterone were obtained by us for JunD protein with quantitative analyses (Hipkaeo et al. 2004).

\section{Discussion}

In the present study, we have demonstrated that, in the adult male and female mouse SMG as well as in the female gland stimulated with androgens, the patterns of expression and localization of menin are essentially the same as those of JunD, which we reported previously (Hipkaeo et al. 2004). Furthermore, menin and JunD are co-precipitated with the respective antibodies, suggesting that they function as a complex in androgen-dependent differentiation of the duct system in the mouse SMG.

Menin has two nuclear localization signals in its C-terminus and binds DNA directly (Guru et al. 1998). With its N-terminal regions, menin binds a variety of proteins, including JunD, NF$\mathrm{KappaB}$, and $\mathrm{Smad} 3$ as transcription factors, cell cycle-associated proteins such as activator of S-phase kinase (ASK), Nm23H1, and P53, and intermediate filament proteins such as glial fibrially acidic protein (GFAP) and vimentin (Poisson et al. 2003; Balogh et al. 2006). JunD was the first protein to be identified as directly interacting with menin (Agarwal et al. 1999). No other member of the Jun and Fos families constituting the AP-1 complex binds menin. The mechanism by which menin inhibits the transcriptional activity of JunD is postulated to be inhibition of extracellular-regulated kinase (ERK)- and Jun $\mathrm{N}$-terminal kinase (JNK)-mediated phosphorylation of JunD (Gallo et al. 2002) or the recruitment of transcription suppressors, histone deacetylases (Gobl et al. 1999). In animal models, deletion of menin is embryonic lethal (Crabtree et al. 2001), whereas mice lacking JunD show retarded postnatal growth and defects in male reproductive func- tion (Thepot et al. 2000). Unlike other members of the AP-1 complex, e.g., c-Jun, JunB, and c-Fos, which are immediate-early gene products whose expression is rapidly and markedly induced by stimulation with various mitogenic agents, JunD is relatively constantly expressed in a variety of cells and tissues and little affected by external stimuli (Hirai et al. 1989; Ryder et al. 1989). Moreover, in contrast with other members of the AP-1 complex being stimulative for cell growth and transformation, JunD is inhibitory for cell growth and transformation (Pfarr et al. 1994). Since menin is also known as a tumor-suppressor protein, inhibition of the transcriptional activity of JunD by menin appears rather paradoxical. However, it has recently been shown that JunD, in the absence of menin, switches from a growth suppressor to a growth promoter (Agarwal et al. 2003). Conversely, menin, in the absence of JunD, stimulates the transcriptional activity of c-Jun, a growth promoter protein (Ikeo et al. 2004). These results suggest that JunD and menin generally function in combination when they exert their biological effects in vivo. A recent study demonstrated that this is the case in bone development, wherein menin and JunD function as a complex in the regulation of osteoblast differentiation (Naito et al. 2005). The present results of ours have reinforced this notion.

The pattern of the expression of JunD/menin in SMG duct cells shown in the present study is rather complicated. Cells in the distal portions of the female SD, which have nuclear immunoreactivity for JunD/menin, lose it after they convert to GCT cells with androgen stimulation. On the other hand, the immunonegative cells in the proximal portions of the female SD become temporarily positive for JunD/menin before they convert to GCT cells. These phenomena suggest that successive accumulation and loss of nuclear JunD/ menin are associated with the differentiation of SD to GCT cells. During the postnatal development of the rodent SMG, ID cells are considered to serve as the stem cells that proliferate and give rise to both SD and acinar cells. GCT cells first occur in the distal portions of the SD by $2 \mathrm{~W}$ postpartum and show a much faster increase in num- 
ber in the male than female gland around 3-5 W (Cutler and Chaudhry 1975; Srinivasan and Chang 1975). In the adult male mouse gland, where most of the SD cells have converted to GCT cells, ID cells are considered to give rise mostly to the adjacent GCT cells and not to acinar cells (Denny et al. 1993). In the adult female gland, the number of GCT cells is very small, but cells in the distal portions of the SD are characterized by the presence, in addition to basal striations, of apical secretory granules similar in appearance to those of GCT cells but smaller in size and number (Caramia 1966). They are designated as striated granular duct (SGD) cells and may represent cells in the process of differentiation from ID to GCT cells (Denny et al. 1999). The present results have demonstrated that nuclear JunD/menin immunoreactivity is present in ID and presumptive SGD cells but absent in GCT and SD cells other than SGD cells, suggesting that nuclear JunD/menin plays roles in the course of cell differentiation from ID to GCT cells. Furthermore, administration of testosterone to female mice newly induces nuclear JunD/menin immunoreactivity in cells located in the proximal portions of the SD at 6-24 hrs, which disappears as these cells convert to GCT cells by $48 \mathrm{hrs}$. We hypothesize that adult female SD cells, unlike ID and SGD cells, normally do not undergo differentiation to GCT cells but are induced by androgens to enter this process. The nuclear accumulation of JunD/menin seems to be critical for this process but no longer required in differentiated GCT cells.

The present study has also demonstrated that, while there is a difference in the levels of $\mathrm{JunD} /$ menin proteins between the male and female SMG and between the female SMG before and after stimulation with androgens, no difference exists in either case in the levels of JunD/ menin mRNA expression. To date, the regulation of expression of JunD and menin themselves has not been clarified. At the transcriptional level, expression of c-Jun is positively regulated by binding of the c-Jun homodimer to an AP-1binding element (TRE) located in the promotor of c-Jun gene itself, whereas expression of c-Fos is induced by a variety of extracellular signals such as serum, hormones, growth factors, and cytokines through their cognate signaling pathways and cis-acting elements located in the c-Fos promotor (Angel and Karin 1991). In contrast, the expression of JunD is thought to be relatively constant in amount and unresponsive to extracellular signals (Hirai et al. 1989; Ryder et al. 1989). The menin gene has no consensus cis-acting elements in its promotor, although its expression is negatively regulated by its product menin itself via a feedback mechanism (Zablewska et al. 2003). On the other hand, the activity of c-Jun is regulated at the posttranscriptional level by phosphorylation. JNK, a factor involved in the Rasmitogen activated protein (MAP) kinase pathway, causes phosphorylation of c-Jun in its N-terminal region and thereby increases the transactivating potential of AP-1 (Pulverer et al. 1991; Karin 1995). Recent studies have demonstrated that the activity of JunD is stimulated in the same way (Gallo et al 2002; Yazgan and Pfarr 2002). In the present study, the phosphorylation of JunD was not examined, but the observed nuclear localization of JunD/menin immunoreactivity presumably represents the activated and functioning state of JunD. The present results suggest that the regulation of JunD/menin in androgen-dependent differentiation of the SMG duct system occurs at the posttranscriptional level and not transcriptional level. The most likely explanation for this phenomenon is that while the level of JunD/menin mRNA does not change, the stability of JunD/ menin proteins changes with the activation of JunD by phosphorylation in an androgen-dependent manner. Thus, the nuclear JunD/menin complex may become stable and accumulate at the beginning, and turn to be unstable and degradated at the end, of the duct cell differentiation to GCT cells. The accumulation and degradation of nuclear JunD were also reported in NIH 3T3 fibroblasts during their quiescence and after stimulation with serum, respectively (Pfarr et al. 1994).

Finally, the present study has reinforced the idea of cross-talk between the androgen/AR system and the AP-1 system, which was suggested in 
our previous paper (Hipkaeo et al. 2004). Androgens, together with other steroid hormones, belong to the family of hydrophobic ligands whose biological effects are mediated by their cognate intracellular receptors. The ligand-bound receptors translocate to the nucleus and serve as transcription factors themselves by binding to specific DNA elements and modulating gene expression (Tsai and O’Malley 1994). In addition to such a classical or genomic model of steroid action, a nonclassical or nongenomic action of steroids, including androgens, which is much faster than the classical one, has recently been noted (Heinlein and Chang 2002; Losel et al. 2003). In this model, steroids bind to receptors located on the plasma membrane and stimulate various cell signaling pathways. These receptors are considered either the classical steroid receptors temporarily associated with membrane proteins, or unidentified transmembrane steroid receptors. Many biological effects, including those of estrogen and progesterone in the female reproductive organs and in the brain, have been interpreted in terms of the nongenomic steroid action (Zhu and Pfaff 1998; Peluso et al. 2001). In regard to androgens, recent studies have revealed the mechanisms of their nongenomic action in different systems. For example, in cultured myotubes, the rapid effects of testosterone leading to the expression of various muscular proteins involve successive activation of the G protein-coupled AR at the plasma membrane, the inositol 1,4,5-triphosphate $\left(\mathrm{IP}_{3}\right)$-mediated $\mathrm{Ca}^{2+}$ signal, and the Ras/MEK/ERK pathway (Estrada et al. 2003). In cultured Sertoli cells, the rapid effects of testosterone leading to spermatogenesis involve the association of the classical AR with membrane Src kinase followed by activation of ERK, and finally of cyclic AMP-response element-binding protein (CREB) (Fix et al. 2004; Cheng et al. 2007). ERK is a major group of factors involved in the MAP kinase signaling pathway. CREB is a transcription factor functioning downstream of not only the protein kinase A (PKA) pathway but also the MAP kinase pathway and calcium-regulated pathways (Shaywitz and Greenberg 1999). In our previous paper, we found in the rat SMG that CREB is expressed abundantly in the nuclei of ID cells and distal SD cells during 3-5 W postpartum but is no longer expressed in the differentiated GCT cells (Amano and Iseki 1998; Kim et al. 2001). Administration of testosterone to immature or hypophysectomized rats caused a temporary rise in the number of CREB-positive SD cells prior to their conversion to GCT cells, suggesting cross-talk between the cyclic AMP/ PKA pathway and the androgen/ AR signaling pathways. The patterns of the expression and localization of menin and JunD in the mouse SMG, as revealed in the present study, are quite similar to those of CREB in the rat SMG. A direct transactivation of JunD/menin expression by the classical AR is unlikely, because no ARE-like consensus sequence has ever been found in the JunD or menin gene, and testosterone does not increase the level of JunD or menin mRNA. As mentioned, the Jun family including JunD is posttranslationally activated by phosphorylation by JNK, another subgroup of the MAP kinase family (Karin 1995; Gallo et al. 2002; Yazgan and Pfarr 2002).

The present observation of an increase in the nuclear immunoreactivity for JunD/menin in the SMG duct system might represent JNK-mediated activation of JunD. ERK and JNK belong to distinct MAP kinase cascades functioning downstream of the membrane-bound protein Ras. As revealed in several other systems, cross-talk between the androgen/AR system and the RasMAP kinase signaling pathway might be responsible for the nongenomic actions of androgens in the androgen-dependent differentiation of the duct system in the mouse SMG. To clarify this issue, further study using pharmacological and molecular biological techniques in cultured cell systems will be necessary.

\section{Acknowledgments}

We thank Mr. S. Yamazaki for technical assistance in the preparation of histological specimens and Ms. Y. Akabori for secretarial assistance. This work was supported by a Grant-in-Aid for Scientific Research from the Ministry of Education, Science and Culture of Japan to SI. We dedicate this paper to Dr. Hisatake Kondo on his retirement from the 
position of Professor, Department of Cell Biology, Graduate School of Medicine, Tohoku University on March 31, 2008.

\section{References}

Agarwal, S.K., Guru, S.C., Heppner, C., Erdos, M.R., Collins, R.M., Park, S.Y., Sagger, S., Chandrasekharappa, S.C., Collins, S.F., Spiegel, A.M., Marx, S.J. \& Burns, A.L. (1999) Menin interacts with the AP1 transcription factor JunD and represses JunD-activated transcription. Cell, 96, 143-152.

Agarwal, S.K., Novotny, E.A., Crabtree, J.S., Weitzman, J.B., Yaniv, M., Burns, A.L., Chandrasekharappa, S.C., Collins, F.S., Spiegel, A.M. \& Marx, S.J. (2003) Transcription factor JunD, deprived of menin, switches from growth suppressor to growth promoter. Proc. Natl. Acad. Sci. USA, 100, 10770-10775.

Amano, O. \& Iseki, S. (1998) Occurrence and nuclear localization of cAMP response element-binding protein in the postnatal development of the rat submandibular gland. Histochem. J., 30, 591-601.

Angel, P. \& Karin, M. (1991) The role of Jun, Fos and the AP-1 complex in cell-proliferation and transformation. Biochim. Biophys. Acta, 1072, 129-157.

Balogh, K., Racz, K., Patocs, A. \& Hunyady, L. (2006) Menin and its interacting proteins: elucidation of menin function. Trends. Endocrinol. Metab., 17, 357-364.

Barka, T. (1980) Biologically active polypeptides in submandibular glands. J. Histochem. Cytochem., 28, 836-859.

Caramia, F. (1966) Ultrastructure of the mouse submaxillary gland. I. Sexual differences. J. Ultrastruct. Res., 16, 333-345.

Chandrasekharappa, S.C., Guru, S.C., Manickam, P., Olufemi, S.E., Collins, F.S., Emmert-Buck, M.R., Debelenko, L.V., Zhuang, Z., Lubensky, I.A., Liotta, L.A., Crabtree, J.S., Wang, Y., Roe, B.A., Weisemann, J., Boguski, M.S., Agarwal, S.K., Kester, M.B., Kim, Y.S., Heppner, C., Dong, Q., Spiegel, A.M., Burns, A.L. \& Marx, S.J. (1997) Positional cloning of the gene for multiple endocrine neoplasia-type 1. Science, 276, 404-407.

Chang, W.W. \& Barka, T. (1974) Stimulation of acinar cell proliferation by isoproterenol in the postnatal rat submandibular gland. Anat. Rec., 178, 203-209.

Chang, C., Salzman, A., Yeh, S., Young, W., Keller, E., Lee, H.J., Wang, C. \& Mizokami, A. (1995) Androgen receptor: an overview. Crit. Rev. Eukar. Gene Expr., 5, 97-125.

Cheng, J., Watkins, S.C. \& Walker, W.H. (2007) Testosterone activates mitogen-activated protein kinase via Src kinase and the epidermal growth factor receptor in Sertoli cells. Endocrinology, 148, 2066-2074.

Chretien, M. (1977) Action of testosterone on the differentiation and secretory activity of a target organ: the submaxillary gland of the mouse. Int. Rev. Cytol., 50, 333-396.

Crabtree, J.S., Scacheri, P.C., Ward, J.M., Garrett-Beal, L., Emmert-buck, M.R., Edgemon, K.A., Lorang, D., Libutti, S.K., Chandrasekharappa, S.C., Marx, S.J., Spiegel, A.M. \& Collins, F.S. (2001) A mouse model of multiple endocrine neoplasia, type 1, develops multiple endocrine tumors. Proc. Natl. Acad. Sci. USA, 98, 1118-1123.

Cutler, L.S. \& Chaundhry, A.P. (1975) Cytodifferentiation of striated duct cells and secretory cells of the convoluted granular tubules of the rat submandibular gland. Am.J. Anat., 143, 201-218.
Denny, P.C., Chai, Y., Klauser, D.K. \& Denny, P.A. (1993) Parenchymal cell proliferation and mechanisms for maintenance of granular duct and acinar cell populations in adult male mouse submandibular gland. Anat. Rec., 235, 475-485.

Denny, P.C., Liu, P. \& Denny, P.A. (1999) Evidence of a phenotypically determined ductal cell lineage in mouse salivary glands. Anat. Rec., 256, 84-90.

Estrada, M., Espinosa, A., Muller, M. \& Jaimovich, E. (2003) Testosterone stimulates intracellular calcium release and mitogen-activated protein kinases via a $G$ protein-coupled receptor in skeletal muscle cells. Endocrinology, 144, 3586-3597.

Fix, C., Jordan, C., Cano, P. \& Walker, W.H. (2004) Testosterone activates mitogen-activated protein kinase and the cAMP response element binding protein transcription factor in Sertoli cells. Proc. Natl. Acad. Sci. USA, 101, 10919-10924.

Gallo, A., Cuozzo, C., Esposito, I., Maggiolini, M., Bonofiglio, D., Vivacqua, A., Garramone, M., Weiss, C., Bohmann, D. \& Musti, A.M. (2002) Menin uncouples Elk-1, JunD and c-Jun phosphorylation from MAP kinase activation. Oncogene, 21, 6434-6445.

Gobl, A.E., Berg, M., Lopez-Egido, J.R., Oberg, K., Skogseid, B. \& Westin, G. (1999) Biochim. Biophys. Acta, 1447, 51-56.

Gresik, E.W. (1980) Postnatal development changes in submandibular glands of rats and mice. J. Histochem. Cytochem., 28, 860-870.

Gresik, E.W. (1994) The granular convoluted tubule (GCT) cell of rodent submandibular gland. Microsc. Res. Technol., 27, $1-24$.

Gubits, R.M., Shaw, P.A., Gresik, E.W., Onetti-Muda, A. \& Barka, T. (1986) Epidermal growth factor gene expression is regulated differently in mouse kidney and submandibular gland. Endocrinology, 119, 1382-1387.

Guru, S.C., Goldsmith, P.K., Burns, A.L., Marx, S.J., Spiegel, A.M., Collins, F.S. \& Chandrasekharappa, S.C. (1998) Menin, the product of the MEN1 gene, is a nuclear protein. Proc. Natl. Acad. Sci. USA, 95, 1630-1634.

Heinlein, C.A. \& Chang, C. (2002) The roles of AR and androgen binding proteins in nongenomic androgen actions. Mol. Endocrinol., 16, 2181-2187.

Hipkaeo, W., Wakayama, T., Yamamoto, M. \& Iseki, S. (2004) Expression and localization of the transcription factor JunD in the duct system of mouse submandibular gland. $J$. Histochem. Cytochem., 52, 479-490.

Hirai, S.I., Ryseck, R.P., Mechta, F., Bravo, R. \& Yaniv, M. (1989) Characterization of junD: a new member of the jun proto-oncogene family. EMBO J., 8, 1433-1439.

Ikeo, Y., Yumita, W., Sakurai, A. \& Hashizume, K. (2004) JunD-menin interaction regulates c-Jun-mediated AP-1 transactivation. Endocr. J., 51, 333-342.

Jacoby, F. \& Leeson, C. (1959) The postnatal development of the rat submaxillary gland. J. Anat., 93, 201-206.

Karin, M. (1995) The regulation of AP-1 activity by mitogenactivated protein kinases. J. Biol. Chem., 270, 1648316486.

Kim, J.-G., Amano, O., Wakayama, T., Takahagi, H. \& Iseki, S. (2001) The role of cyclic AMP response element-binding protein in testosterone-induced differentiation of granular convoluted tubule cells in the rat submandibular gland. Arch. Oral Biol., 46, 495-507.

Losel, R.M., Falkenstein, E., Feuring, M., Schultz, A., Tillmann, H.C., Rossol-Haseroth, K. \& Wehling, M. (2003) Nongenomic steroid action: controversies, questions, and answers. 
Physiol. Rev., 83, 965-1016.

Maruyama, K., Tsukada, T., Hosono, T., Ohkura, N., Kishi, M., Honda, M., Nara-Ashizawa, N., Nagasaki, K. \& Yamaguchi, K. (1999) Structure and distribution of rat menin mRNA. Mol. Cell. Endocrinol., 156, 25-33.

Morrell, J.I., Gresik, E.W. \& Barka, T. (1987) Autoradiographic localization of dihydrotestosterone binding in the major salivary glands and other androgen-responsive organs of the mouse. J. Histochem. Cytochem., 35, 1053-1058.

Naito, J., Kaji, H., Sowa, H., Hendy, G.N., Sugimoto, T. \& Chihara, K. (2005) Menin suppresses osteoblast differentiation by antagonizing the AP-1 factor, JunD. J. Biol. Chem., 260, 4785-4791.

Peluso, J.J., Fernandez, G., Pappalardo, A. \& White, B.A. (2001) Characterization of a putative membrane receptor for progesterone in rat granulosa cells. Biol. Reprod., 65, 94-101.

Pfarr, C.M., Mechta, F., Spyrou, G., Lallemand, D., Carillo, S. \& Yaniv, M. (1994) Mouse JunD negatively regulates fibroblast growth and antagonizes transformation by ras. Cell, 76, 747-760.

Pinkstaff, C.A. (1980) The cytology of salivary glands. Int. Rev. Cytol., 63, 141-161.

Poisson, A., Zablewska, B. \& Gaudray, P. (2003) Menin interacting proteins as clues toward the understanding of multiple endocrine neoplasia type1. Cancer Lett., 189, 1-10.

Pulverer, B.J., Kyriakis, J.M., Avruch, J., Nikolakaki, E. \& Woodgett, J.R. (1991) Phosphorylation of c-jun mediated by MAP kinases. Nature, 353, 670-674.

Ryder, K., Lanahan, A., Perez-Albuerne, E. \& Nathans, D. (1989) JunD: A third member of the Jun gene family. Proc. Natl. Acad. Sci. USA, 86, 1500-1503.

Sar, M., Lubahn, D.B., French, F.S. \& Wilson, E.M. (1990) Immunohistochemiccal localization of the androgen receptor in rat and human tissues. Endocrinology, 127, 3180-3186.

Shaywitz, A.J. \& Greenberg, M.E. (1999) CREB: A stimulus- induced transcription factor activated by a diverse array of extracellular signals. Annu. Rev. Biochem., 68, 821-861.

Srinivasan, R. \& Chang, W.W.L. (1975) The development of the granular convoluted duct in the rat submandibular gland. Anat. Rec., 182, 29-40.

Thepot, D., Weitzman, J.B., Barra, J., Segretain, D., Stinnakre, M.-G., Babinet, C. \& Yaniv, M. (2000) Targeted disruption of the murine junD gene results in multiple defects in male reproductive function. Development, 127, 143-153.

Tsai, M.J. \& O’Malley, B.W. (1994) Molecular mechanisms of action of steroid/thyroid receptor superfamily members. Annu. Rev. Biochem., 63, 451-486.

Vogt, P.K. \& Bos, T.J. (1990) Jun oncogene and transription factor. Adv. Cancer Res., 55, 1-35.

Wakayama, T., Kato, Y., Utsumi, R., Tsuji, A. \& Iseki, S. (2006) A time-and cost-saving method of producing rat polyclonal antibodies. Acta Histochem. Cytochem., 39, 79-87.

Wautot, V., Khodaei, S., Frappart, L., Buisson, N., Baro, E., Lenoir, G.M., Calender, A., Zhang, C.-X. \& Weber, G. (2000) Expression analysis of endogenous menin, the product of the multiple endocrine neoplasia type 1 gene, in cell lines and human tissues. Int. J. Cancer, 85, 877-881.

Yazgan, O. \& Pfarr, C.M. (2002) Regulation of two JunD isoforms by Jun N-terminal kinases. J. Biol. Chem., 277, 29710-29718.

Zablewska, B., Bylund, L., Mandic, S.A., Fromaget, M., Gaudray, P. \& Weber, G. (2003) Transcription regulation of the multiple endorine neoplasia type 1 gene in human and mouse. J. Clin. Endocrinol. Metab., 88, 3845-3851.

Zhou, Z.-X., Wong, C.-I., Sar, M. \& Wilson, E.M. (1994) The androgen receptor: an overview. Rec. Prog. Horm. Res., 49, 249-274.

Zhu, Y.-S. \& Pfaff, D.W. (1998) Differential regulation of AP-1 DNA binding activity in rat hypothalamus and pituitary by estrogen. Mol. Brain Res., 55, 115-125. 